\title{
Dielectric mirrors for high power laser applications
}

\author{
K V S R APPARAO \\ Spectroscopy Division, Bhabha Atomic Research Centre, Trombay, Bombay 400085, India

\begin{abstract}
Development of low loss dielectric high refiecting mirrors for high power laser applications presents some problems in selecting suitable thin film materials and in understanding their optical constants. Some of these problems have been solved by a systematic study of the dependence of optical constants on different evaporation parameters for a number of thin film materials. Using the data thus obtained high reflecting dielectric mirrors for different laser applications in the UV, visible and near-infrared regions were successfully developed indigenously by the method of vacuum evaporation.
\end{abstract}

Keywords. Mirrors; lasers; thin films; optics; multilayers; coatings.

\section{Introduction}

With correct choice of thin film constants, film thicknesses and number of films, it is possible to design different dielectric mirrors and other thin film devices (Dobrowolski 1965, 1981; Apparao 1977). But practical realization of low loss, stress free and hard thin film devices which can withstand high power lasers presents some problems (Pawlewicz et al 1980; Carniglia 1981; Kuster and Ebert 1980). Selection of appropriate thin film materials having the required optical and mechanical properties, knowledge of optical losses and constants and their dependence on the process parameters are some of the involved problems. In order to meet the specific needs of research activities using lasers some of these problems have been solved and different thin film devices including dielectric mirrors for high power laser applications were developed indigenously. Some of the important results derived during the development work are presented in this paper.

\section{Thin film devices development}

It is well known that a multilayer dielectric thin film device is made up of atleast two materials and depending on the application the films of each material should have the desired refractive index, transmission, scattering, thickness, stress, hardness, defects, optical losses, resistance to laser radiation etc. Unfortunately despite all the advances in materials science and sophisticated instrumentation during the last few years, it is difficult to achieve all the desired film properties in any process because the film growth during the process of evaporation, as is well known, is complex and depends upon different process parameters like evaporation method, rate of evaporation, substrate temperature, ambient pressure, vapour angle, vapour chopping, glow discharge, starting material, substrate material etc. For example, for laser applications, optical loss of the coatings is one of the important factors to be controlled during the evaporation 
process. These losses, which include losses due to absorption, adsorption, scattering and fluorescence, depend upon the bulk absorption, stoichiometry, voids in the structure, surface roughness, rough internal boundaries, density changes, pin holes, cracks, microdust etc in the films which are all process-dependent except the bulk absorption. So exact and reproducible process and chamber parameters which give the desired film properties with the specified tolerance limits are very essential to develop high quality thin film devices for laser applications. The present situation is such that although basic optical properties of different thin film materials are available (Jenkins 1958; Hass and Ritter 1967; Macleod 1969; Ritter 1975; Pulker 1979), full details of optical constants and mechanical properties of the films and their dependence on process parameters are not available in the voluminous literature published in the field, particularly for the films in the uv region from $240 \mathrm{~nm}$ to $400 \mathrm{~nm}$. This is because most of the parameters are considered as trade secrets and patents and are not published. The few results published are not exactly reproducible and are different for different experimental set-ups. In addition human element in the form of experience, skill and judgement plays a role in achieving the required film properties in the given process.

In our programme to develop thin film devices indigenously, studies have been undertaken to evaluate all necessary film data for different thin film materials like $\mathrm{TiO}_{2}$, $\mathrm{CeO}_{2}, \mathrm{Al}_{2} \mathrm{O}_{3}, \mathrm{MgF}_{2}, \mathrm{SiO}_{2}, \mathrm{MgO}, \mathrm{Ta}_{2} \mathrm{O}_{5}, \mathrm{Na}_{3} \mathrm{AlF}_{6}, \mathrm{ZrO}_{2}$ etc. using the method of vacuum evaporation. Using the data thus obtained low loss, stress force and hard high reflecting mirrors of conventional design having reflection as high as $99.5 \%$ with losses as low as $0.5 \%$ were developed for different wavelengths ranging from 300 to $1060 \mathrm{~nm}$. The coatings developed are in constant use in our laboratories and are found to withstand the available lasers operating upto $1 \mathrm{MW}$ maximum power with $10 \mathrm{nsec}$ pulse widths. High reflecting mirrors developed so far include the coatings working at $\mathrm{XeCl}, \mathrm{N}_{2}, \mathrm{HeCd}$, visible dye, II YAG, $\mathrm{Ar}^{+}, \mathrm{Cu}$ vapour, $\mathrm{HeNe}$ and $\mathrm{YAG}$ glass laser wavelengths.

\section{Development work}

Space does not permit a discussion of the entire development work and so some details of the investigations carried out for developing the dielectric mirrors for the Uv region from $240 \mathrm{~nm}$ to $400 \mathrm{~nm}$ are presented in this paper. The uv coatings were developed, using $\mathrm{ZrO}_{2}$ as high index and $\mathrm{SiO}_{2}$ as low index materials, by the method of reactive evaporation. The results concerning the optical losses of $\mathrm{ZrO}_{2}$ films prepared under different evaporation parameters are given. The dependence of the optical losses and constants on the rate of evaporation, ambient oxygen pressure, substrate temperature, film thickness and chopping the vapour before reaching the substrate have been studied and the results of the most significant evaporation parameters are briefly discussed and the results presented.

\subsection{Experimental}

$\mathrm{ZrO}_{2}$ films were deposited on a $25 \mathrm{~mm}$ diameter fused silica substrates by evaporating optical grade $\mathrm{ZrO}_{2}$ using the electron beam gun in a conventional $500 \mathrm{~mm}$ vacuum coating unit. The chamber was evacuated to better than $2 \times 10^{-6}$ mbar before evaporating the material. For reactive evaporation IOLAR grade pure oxygen from a high pressure cylinder was admitted into the chamber and maintained at the required 
value ranging from $3 \times 10^{-4} \mathrm{mbar}$ to $5 \times 10^{-6} \mathrm{mbar}$ by controlling the needle valve and pressure regulating valves. The substrate was heated to the assigned temperatures ranging from $50^{\circ} \mathrm{C}$ to $400^{\circ} \mathrm{C}$ and the evaporation rate ranging from $1 \AA / \mathrm{sec}$ to $100 \AA / \mathrm{sec}$ was measured and controlled with the quartz crystal monitor. Chopped films were prepared by introducing suitable rotating mask between the substrate and the source. $A$ total of 35 samples were prepared for the present studies, each with different evaporation conditions. For all the samples prepared uniformity of film thickness over the whole surface was found to be within $\pm 2 \%$ of the average thickness. The transmittance spectrum of each substrate was recorded before and after depositing the film using double beam spectrophotometer (Hitachi model 330). The optical losses $L$ were taken as the difference of transmission peak maxima and the substrate transmission at the respective peak wavelengths. Refractive index $n$, physical thickness $t$ and the effective extinction coefficient $k$ of each sample film were deduced by the method of Swanepoel (1983).

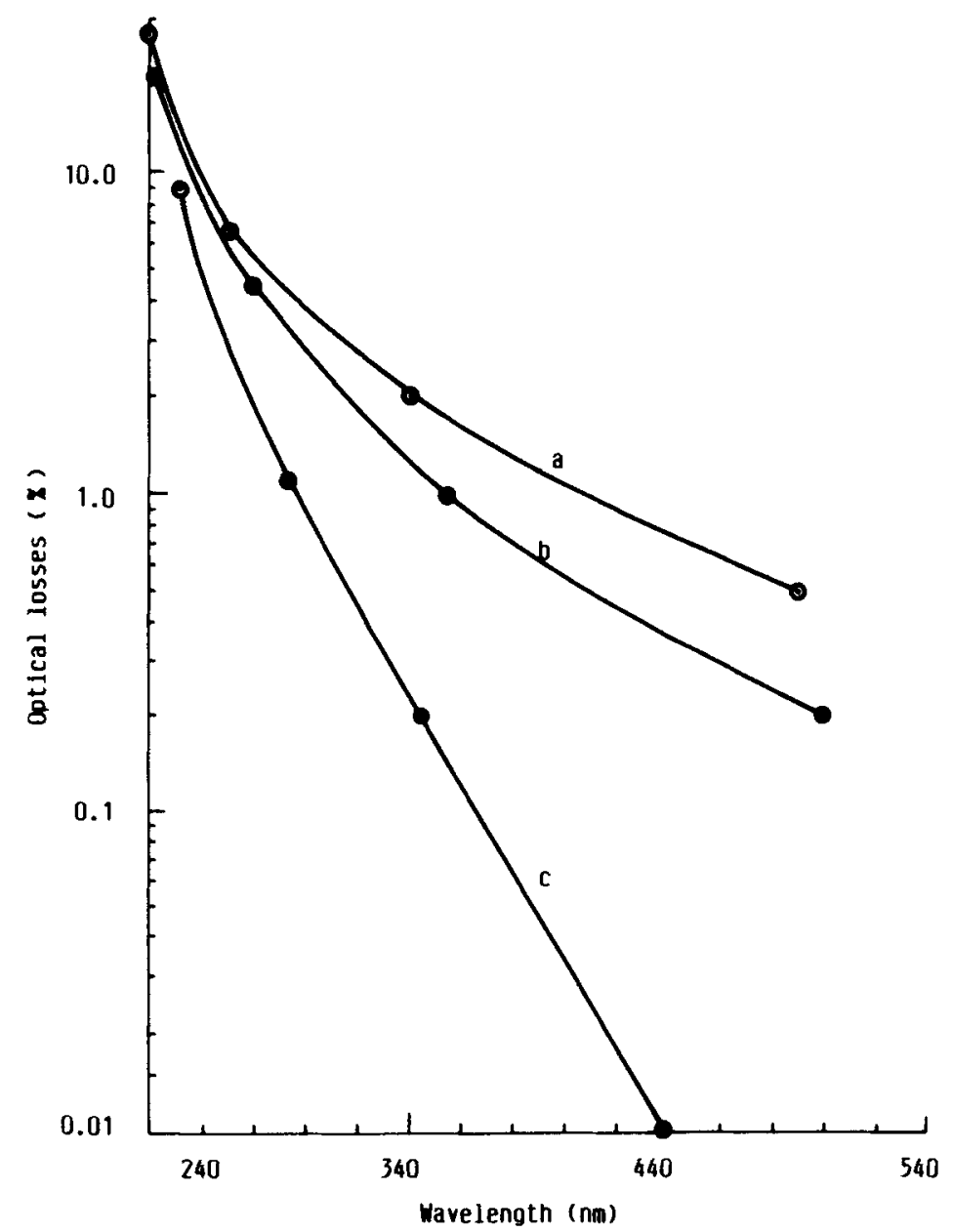

Figure 1. Dependence of optical losses of $\mathrm{ZrO}_{2}$ films on rate of evaporati in. (a) $20 \AA / \mathrm{sec}$, $t=250 \mathrm{~nm}$, (b) $10 \mathrm{~A} / \mathrm{sec}, t=275 \mathrm{~nm}$ and (c) $5 \mathrm{~A} / \mathrm{sec}, t=320 \mathrm{~nm}$ 


\subsection{Results and discussion}

The measured percentage losses $L$ were plotted against the wavelength $\lambda$ for each set of films prepared under identical conditions with one parameter variable. Figure 1 shows one such plot where the variation of optical losses is shown for films prepared at different evaporation rates. All the films shown in figure 1 were prepared at the same ambient oxygen pressure $\left(2 \times 10^{-4} \mathrm{mbar}\right)$ and substrate temperature $\left(260^{\circ} \mathrm{C}\right)$. As can be seen from figure 1 the optical losses are minimum for $\mathrm{ZrO}_{2}$ films evaporated at $5 \AA / \mathrm{sec}$. The present investigation also indicated that the losses are further reduced as expected at higher substrate temperatures and low oxygen ambient pressures. It was also found that the losses in the visible region (where the absorption is negligible) remained almost constant with increasing film thickness indicating that the losses were greater due to surface scattering than bulk scattering. Such changes can be attributed to changes in the film structure, grain size, density fluctuations, stoichiometry and the extent of reoxidation of the film (Pulker 1976; Baumeister and Arnon 1977). For the best $275 \mathrm{~nm}$ thick $\mathrm{ZrO}_{2}$ films prepared the optical constants $L, n$ and $k^{\prime}$ respectively at different uv laser wavelengths are found to be $8 \%, 2 \cdot 35,7 \cdot 0 \times 10^{-3}$ at $248 \mathrm{~nm}, 0.6 \%, 2 \cdot 16,4 \cdot 7 \times 10^{-4}$ at $308 \mathrm{~nm}, 0.24 \%, 2.12,1.2 \times 10^{-4}$ at $337 \mathrm{~nm}$ and $0.14 \%, 2.11,8.8 \times 10^{-5}$ at $351 \mathrm{~nm}$. The data from the present investigations were used successfully to develop uv coatings for laser applications. Full details of the present investigations and those connected with other materials for developing dielectric mirrors for visible and near infrared region will be published elsewhere.

\section{References}

Apparao K V S R 1977 Indian J. Pure. Appl. Phys. 15270

Baumeister P and Arnon O 1977 Appl. Opt. 16439

Carniglia C K 1981 Thin Solid Films 77225

Dobrowolski J A 1965 Appl. Opt. 4937

Dobrowolski J A 1981 Appl. Opt. 2074

Hass G and Ritter E 1967 J. Vac. Sci. Technol. 471

Jenkins F A 1958 J. Phys. Rad. 19301

Kuster $\mathrm{H}$ and Ebert $I 1980$ in Laser induced damage in optical materials (eds) H E Bennett, A A Glass, A H Guenther and B E Newnam (Washington: Nat. Bur. Stand.) Spec. Publ. 568, 269

Macleod H A 1969 in Thin film optical filters (London: Adam Hilger) 316

Pawlewicz W T, Hays D D and Martin P M 1980 Thin Solid Films 73169

Pulker H K 1976 Thin Solid Films 34343

Pulker H K 1979 Appl. Opt. 181969

Ritter E 1975 in Physics of thin films (New York: Academic Press) Vol. 8

Ritter E 1981 Appl. Opt. 2021

Swanepoel R 1983 J. Phys. E16 1214 